\title{
Crops Diagnosis Using Digital Image Processing and Precision Agriculture Technologies*
}

\section{Diagnóstico de Cultivos Utilizando Procesamiento Digital de Imágenes y Tecnologías de Agricultura de Precisión}

\author{
DOI:http://dx.doi.org/10.17981/ingecuc.11.1.2015.06
}

Research Article - Reception Date: July 22, 2014 - Acceptance Date: March 2, 2015

Andrés Fernando Jiménez López

Master of Science, Universidad de los Llanos. Villavicencio (Colombia).jimenez@unillanos.edu.co

Juan Mauricio Salamanca

PhD in Engineering, Universidad Pedagógica y Tecnológica de Colombia. Sogamoso (Colombia). juan.salamanca@uptc.edu.co

Melanie Jisell Quiroz Medina

Electronic Engineer, Universidad Pedagógica y Tecnológica de Colombia. Sogamoso (Colombia). melaniejisell@gmail.com

Oscar Eduardo Acevedo Pérez

Electronic Engineer, Universidad Pedagógica y Tecnológica de Colombia. Sogamoso (Colombia).oscareduacevedo@gmail.com

To cite this paper:

A.F. Jiménez López, J. M. Salamanca, M. J. Quiroz Medina and O. E. Acevedo Pérez. "Diagnóstico de Cultivos Utilizando Procesamiento Digital de Imágenes y Tecnologías de Agricultura de Precisión”, INGE CUC, vol. 11, no. 1, pp. 63-71, 2015. DOI: http://dx.doi.org/10.17981/ingecuc.11.1.2015.06

\begin{abstract}
This paper presents the results of the design and implementation of a system for capturing and processing images of agricultural crops. The design includes the development of software and hardware for image acquisition using a model helicopter equipped with video cameras with a resolution of $640 \times 480$ pixels. A software application was developed for performing differential correction of errors generated by the Global Positioning System (GPS) and for allowing the monitoring of the position of the helicopter in real time. A telemetry system consisting of an inertial measurement unit, a magnetometer, a pressure and altitude sensor, one GPS and two photo cameras were developed. Finally, image processing software was developed to determine some vegetation indexes and generation of three-dimensional maps of crops.
\end{abstract}

Keywords - Agriculture, Electrodynamics, Engineering, Light, Optics, Waves, Vegetation.

\begin{abstract}
Resumen-- Este artículo presenta los resultados del diseño e implementación de un sistema de captura y procesamiento de imágenes de cultivos agrícolas. El diseño incluye el desarrollo de software y hardware para la adquisición de imágenes mediante un helicóptero de aeromodelismo equipado con cámaras de resolución de 640×480 pixeles. Se desarrolló una aplicación en software para realizar la corrección diferencial de errores generados por el Sistema de Posicionamiento Global (GPS por sus siglas en inglés), permitiendo también el monitoreo de la posición del helicóptero en tiempo real. Se desarrolló un sistema de telemetría compuesto de una unidad de medida inercial, un magnetómetro, un sensor de presión y altitud, un GPS y dos cámaras fotográficas. Finalmente se elaboró un software de procesamiento de imágenes para determinar algunos índices de vegetación y generación de mapas tridimensionales de los cultivos.
\end{abstract}

Palabras claves - Agricultura, Electrodinámica, Ingeniería, Luz, Óptica, Ondas, Vegetación.

\footnotetext{
* Research paper deriving from the research Project "Sistema de Adquisición y Análisis de información multiespectral de sensores remotos mediante un Vehículo Aéreo no Tripulado, para aplicaciones de Agricultura de Precisión". Funded by Universidad de los Llanos. Starting date: October 2013. Ending date: September 2014. And from the research Project "Diseño e Implementación de un Sistema de Sensado Multiespectral remoto para aplicaciones de Agricultura de Precisión". Funded by Universidad Pedagógica y Tecnológica de Colombia. Starting date: April 2013. Ending date: April 2014.
} 


\section{INTRODUCTION}

Precision Agriculture (PA) is an integrated system based on crop information, designed to increase production efficiency, productivity and profits, and in turn, reduce impacts on the preservation of life and the environment. PA differs from conventional agriculture on the fact that it allows action on farming management, allowing the farmer to have a new crop management perspective with which to make more rational decisions in managing their crops.

Usually in the field of PA, satellite images are used for analysis of land, although the satellite can detect information from a wide area, the spatial resolution of the satellite image in low-cost products is: $1000 \mathrm{~m}, 500 \mathrm{~m}$ or $250 \mathrm{~m}$ for MODIS product data, and $20 \mathrm{~m}$ for Landsat and ASTER products, among others. These resolutions make it difficult to determine the characteristics for segment in an image of the soil and crops because of the detail of the information that can be taken [1]. The data acquired by these products is not suitable for detecting the state of crops in small batches such as small land holdings or micro-farms, or when there is cloud cover, due to reflectance of visible radiation in the clouds. In addition, other satellite products with higher spatial resolution IKONOS (4 meters) and QuickBird (1 meter) are too expensive for ordinary users [2].

Another disadvantage of the methodology to analyze coverage by satellite imagery is the time it takes to acquire a satellite image of the same sector for the spatio-temporal analysis of phenological variables in crops, making it impossible to detect changes at the right time. Many applications use data from remote sensing or mobile platforms for monitoring and controlling natural phenological variables seeking to improve the production and environmental sector, therefore, this paper presents the development of a useful tool for determining phenology parameters of agricultural crops through the acquisition and processing of images that would adequately solve the difficulty of obtaining field information with spatial and temporal adequate resolutions.

\section{A. Precision Agriculture (PA)}

Initially PA was used for large tracts of land; its development arose from the growing environmental concerns, the need to give proper use to soils and produce quality food in a sustainable and respectful way towards the environment.

PA is a sustainable alternative system and a useful management strategy in production processes; it is an agronomic management concept of farming plots covering all techniques, methods of cultivation and field management. It incorporates Information technology with specialized methods and tools for data collection and its study based on spatial and temporal variables. This is done through multiple sources, given the variety in the area (Global Positioning Systems -GPS-, instrumentation systems and data acquisition, electronics, microelectronics, wireless technology, sensors, controllers and equipment, among others), with the purpose to collect, collate, analyze and chart the information of what happens or may happen in soils or crops, and so develop strategies to address the constraints of the place [3], [4].

\section{B. Tools used by Precision Agriculture}

Along with biotechnology, PA is one of the most important technological changes experienced by agriculture in recent years [3], [4]. The tools used by PA are intended to provide higher quality, control, data logging and higher precision when it comes to defining different management alternatives or making future decisions, in order to help make agriculture more profitable through increase in yield value (quantity or quality) and reduction in the number of inputs. Information technology provides tools for obtaining useful data in managing soils and crops on the variability present within an area by specifying the management of production processes. Among others, the main technological tools used in PA include weather stations, remote sensing, Geographic Information Systems (GIS), performance monitors, Global Navigation Satellite Systems (GNSS), Global Positioning Systems (GPS) and data bases.

These technologies are used for verifying diagnostic processes (mapping of coverage, soil, irrigation lines, roads, boundaries, dimensions, infrastructure, etc.); strengthening works or projects in the short, medium and long term (installing an irrigation system line, establishing a new plot or a reservoir); mapping of growth, development, and crop yielding; for the planning and execution of tasks related to the application of inputs, since they help specify which sites, in what amounts and when those inputs can be used.

\section{Global Positioning System - GPS}

Some authors like Sugiura, Gonzalez and Peñafel [2], [4], [5], have undertaken the task of defining the Global Positioning System, known by its acronym: GPS. It began as a system of satellite radio navigation operated by the United States' Department of Defense in the $70 \mathrm{~s}$, for the launch of geostationary satellites around the earth for the purpose of guiding missiles from mobile platforms and locating military objectives accurately and fast in enemy countries. However, nowadays it has fostered the emergence of new sources of development as AP.

The protocol used by the GPS system is NMEA, developed by the National Marine Electronics Association to communicate with a particular program 
that is installed on a computer or on a mobile device (PDA, mobile phone, etc.).

The differential positioning occurs when two or more GPS instruments are involved with the aim to eliminate common positioning mistakes (selective availability) and is done by calculating coordinate increments from reference equipment to a mobile one.

\section{Unmanned Airborne Systems}

The use of airborne platforms in civilian applications hinders the existence of a consensus on its definition; therefore, there exists a variety of names: RPA (Remotely Piloted Aircraft), or UA (Unmanned Aircraft or Uninhabited Aircraft) in the past, and UAV (Unmanned Aerial Vehicle), or UAS (Unmanned Aircraft System) nowadays. These terms refer to the absence of crew on the vehicle which is not necessarily a synonym of autonomy. Unmanned aerial vehicles allow autonomous or semi-autonomous development of different types of missions that range from fields of defense and security to agriculture and environment [6].

\section{E. Remote Sensing Systems}

Remote sensing is the measurement or acquisition of information about an object or phenomenon by a team that is not in contact with that object; in agriculture, these systems are based on the interaction of electromagnetic radiation with the soil or the plant where the radiation reflected or emitted by the crops or the characteristic spectral signature is measured [7]. Remote sensing applications in PA are classified by the type of platform used for the sensor: directly from the ground level or by means of devices that are boarded on aircraft, or satellite [8]. Aerial images provide a wealth of information at a reasonable cost and its analysis allows modeling various agronomic parameters that determine the production and the intelligent application of herbicides and fertilizers to differentiate weeds from crops and thus generate yield maps for management during and after the growing season. This technology has countless applications in various fields, from scientific and ecological to economic, urban and social studies [9].

\section{F. Crop Diagnosis}

The amount of radiation reflected from plants is inversely related to the radiation absorbed by pigments, and varies with the wavelength of the incidental radiation. Plant pigments such as chlorophyll strongly absorb radiation in the visible spectrum (400 to 700 nanometers); in contrast, plants are highly reflective in the near infrared (NIR 700 to $1300 \mathrm{~nm}$ ) in areas with leaf density and effects of the tree canopy structure [10]. Besides reflectance, transmittance, absorption, leaves of plants have thermal emission (fluorescence energy) with which water stress in crops can be defined, since radiation emission is the temperature response of the leaf and canopy, which varies with the air temperature and the rate of evapotranspiration.

Vegetation indexes such as NDVI (Normalized Difference Vegetation Index), SVI (Simple Vegetation Index) and EVI (Enhanced Vegetation Index) are most commonly used in studies of remote sensing for vegetation classification [8]. A wide range of other indices have been developed to offset the effects of soil including: Soil-Adjusted Vegetation Index (SAVI), Green Soil Adjusted Vegetation Index (GSAVI), Optimized Soli Adjusted Vegetation Index (OSAVI) and Green Optimized Soil Adjusted Vegetation Index (GOSAVI).

The reflective properties of vegetation depend on three types of variables: the canopy structure (characterized by foliar index, the orientation of the leaves and their distribution and size), the optical properties of the reflective elements (stems, leaves, flowers and fruits); and the geometry of observation, which is determined by the relative orientation sunsurface, and the position of the sensor with respect to the latter [11].

\section{System Description}

As a solution to the disadvantages of using satellite images in small agricultural areas, the aim of this project is to develop a system able to acquire, analyze and store information to make crop diagnosis with aerial imagery capture, thus minimizing operating costs, getting higher resolution and better viewing range of the specific area, in order to identify the terrain variability and certain present phenological conditions. A model helicopter is equipped with two cameras (visible and near infrared spectrum), a GPS system for differential field correction, besides, pressure and altitude sensors, an IMU (Inertial Measurement Unit) and a magnetometer to monitor the helicopter status in real time. The crop information obtained wirelessly is processed by software to be interpreted and analyzed for its diagnosis through vegetation indices and generation of 3D maps which in turn allows setting the DGPS location of the acquired images and sensor parameters at the moment of the capturing.

\section{A. System Structure}

The system consists of a field station and a base station. The field station is composed of: a model aircraft, an embedded system and a video camera for monitoring. The base station is responsible for 
administering and managing the data collected in the field by two computers.

Specifically, the field station combines a model aircraft (9053 Volitation helicopter) with two cameras (visible spectrum: HD 3000 and infrared spectrum: LS-Y201-TTL-Infrared), GPS (VENUS638FLPX), inertial measurement units (gyro and accelerometer) IMU MPU 6050, pressure and altitude sensor (LPS331AP), electronic compass (CMPS10), batteries (LiPo type and GP 9V 1604S 6 F22) and a voltage regulator (LM2596).

The processing and transmission of information to the base station via wireless is performed using BeagleBone Black embedded system. Additionally, the model aircraft has a video camera (1/3 CMOS Color, Screw type) with transmitter included that allows monitoring the flight path and image capture from the base station in real time.

The base station is responsible for administering and managing the data collected in the field by two computers: Computer1 equipped with the telemetry station for receiving the information from the sensors (IMU, GPS, compass, pressure and altitude; embedded system status and battery level) and Computer 2 with GPS base station (for the process of capturing the GPS reference position for differential correction) and video tracking of the UAV flight.

In acquiring the video, the $\mathrm{RF}$ receiver from the video camera (1/3 CMOS Color, Screw type) is connected to a frame grabber (EasyCAP DC60). For receiving GPS information (VENUS638FLPX) at the base, a USB converter to UART (PL2303) is used.

Computador1 receives data concerning the position of the model aircraft, the acquired photographs and the field station system status, which is administered by the embedded system. This system is able to control, store, pre-process and send the information wirelessly to the telemetry station application where it is displayed through a web interface, real-time monitoring of sensors (IMU, GPS, compass, pressure and altitude) and the embedded system information ( battery level and system status.) Additionally, it displays captures taken by visible and near infrared spectrum cameras generating a text file (.txt) with the information from the sensors in the moment when the photographic capture was done, allowing downloading of this information (images, .txt file.)

Computador2 collects GPS information from the base station through the GPS base platform interface developed in Python, in charge of capturing, decoding, storing and displaying the NMEA code that the GPS sends. The Ulead Video Studio SE DVD (video editor software) displays the path of the UAV in real time, as support for its location and reference when capturing images and other data on the aerial platform.

With regard to data processing and delivery of results, Indexes Platform is a software program de- veloped in Python for the respective analysis and support of the crop diagnosis. The Index Platform take .txt file delivered by the GPS platform base, the telemetry station and the images captured by the cameras of visible and infrared spectrum; then performs the calculation of vegetation indexes. It graphically shows the result of each one in images with and without tempering to improve vision of phenological characteristics, it also shows the segmentation of the land to differentiate crop from soil and generates a 3D image of its topography. Using this software, it is also possible the acquisition of the position data of the GPS field station and the base station to set the coordinates where the images were captured and with them, make the respective DGPS correction and display the sensors status to know the inclination, direction and altitude.

\section{B. Embedded System}

The embedded system is the result of the instrumentation in the UAV. This system comprises an instrumentation module and the software architecture of the embedded system. The instrumentation module is responsible for managing the peripherals connected to it (see Fig. 1); and the software architecture of the embedded system diagrams the functions used by the processor to perform the acquisition and management of the data by the sensors, and characterizes the libraries used to acquire sensor data and the process that makes the development board to deliver those data to servers for its administration.

The acquisition of data from sensors uses three libraries: LIBFX, V4L and LIP_LSY201. The LIBFX library is developed in the programming language $\mathrm{C}++$, it contains different drivers for managing embedded system peripherals among which are: UART_GPS, I2C_IMU, I2C_LPS, ADC_NIVEL and additional libraries for processing such as LNMEA and FILTROAHRS. The V4L library is responsible for the configuration and management of video controllers, also written in $\mathrm{C}++$ language. Finally, the LIP_LSY201 library developed in Python code sets the LSY201 or NIR (infrared) camera.

\section{Telemetry Station}

It is responsible for displaying and capturing the data collected in the field by the embedded system and administered by WEB_SERVER that allows through the of Telemetry Station website (see Fig. 2) developed in Node.js source code (for layout and visualization of sensor data) and JavaScript (display of captured images), monitoring the UAV in real time and the user's access by TCPIP protocol.

The GPS base station allows setting a benchmark and performing DGPS differential correction of data collected by the field station (see Fig. 3). 


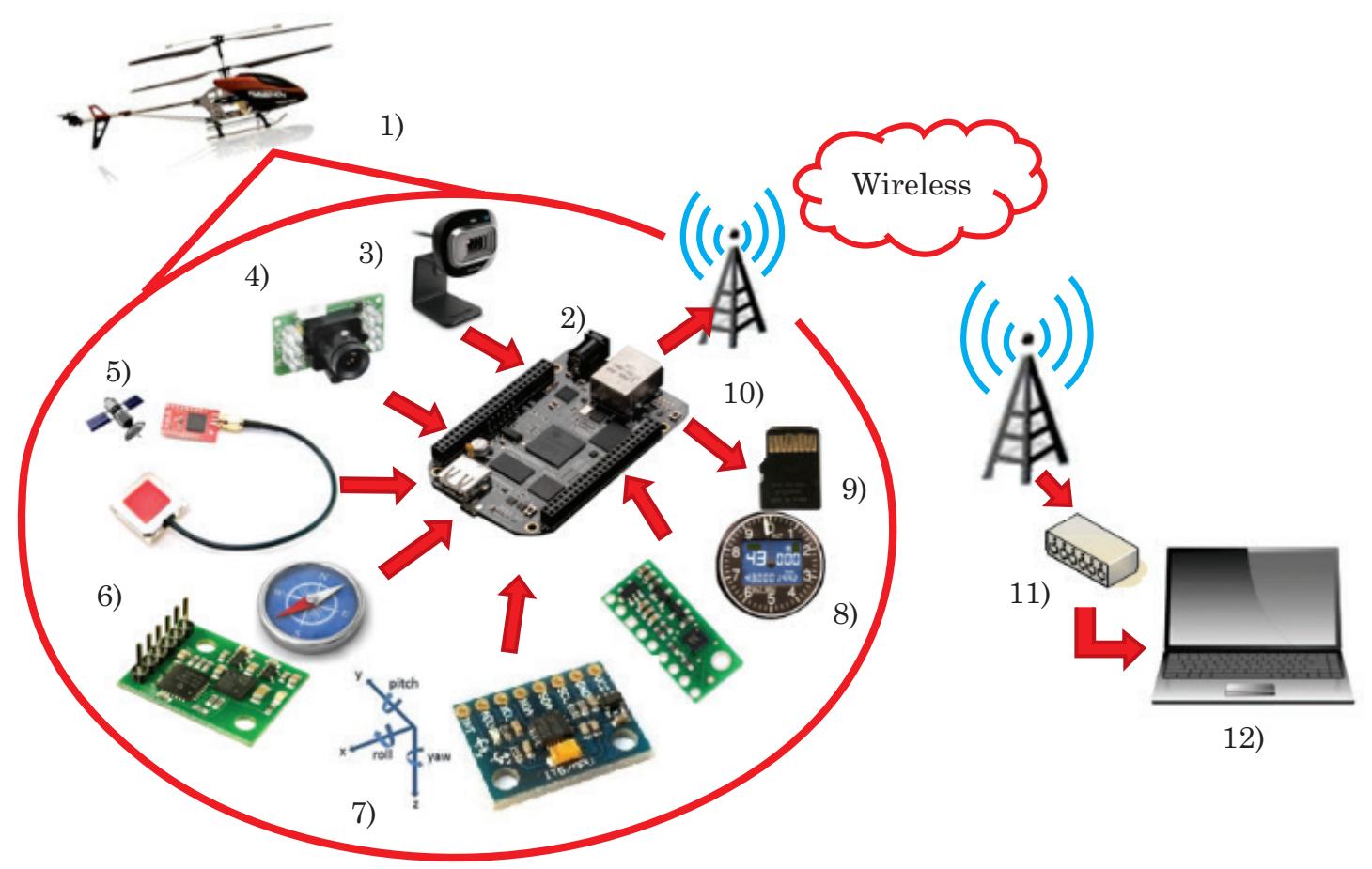

Fig.1. Instrumentation module of the embedded system. 1) Model aircraft; 2) BeagleBone Black; 3) Visible spectrum camera; 4) Infrared camera; 5) GPS field station; 6) Electronic compass; 7) IMU; 8) Pressure and altitude sensor; 9) SD card;10) Wireless communication; 11) Router; 12) Base station computer. Source: Authors.

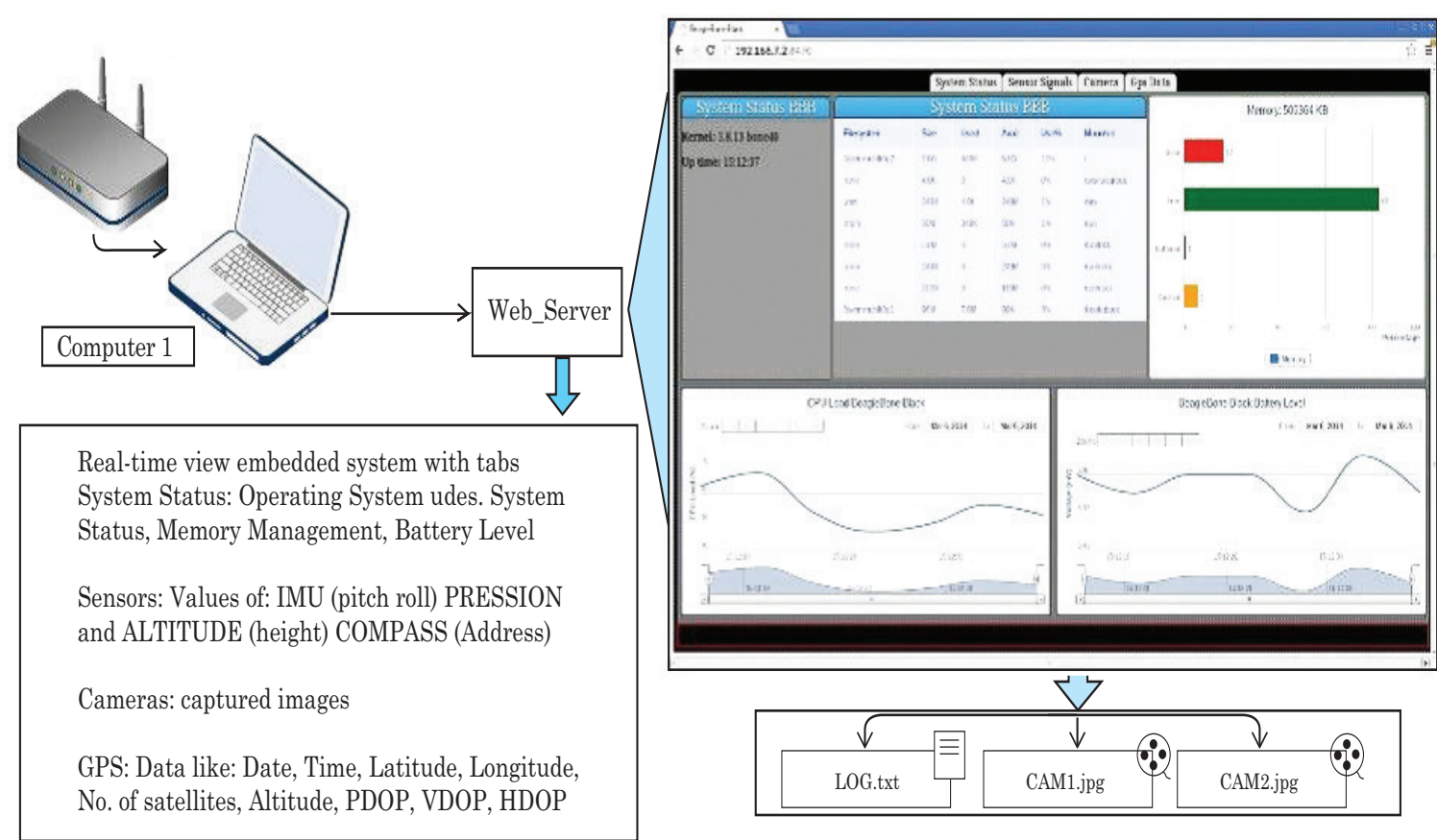

Fig.2. System structure of the telemetry station. 


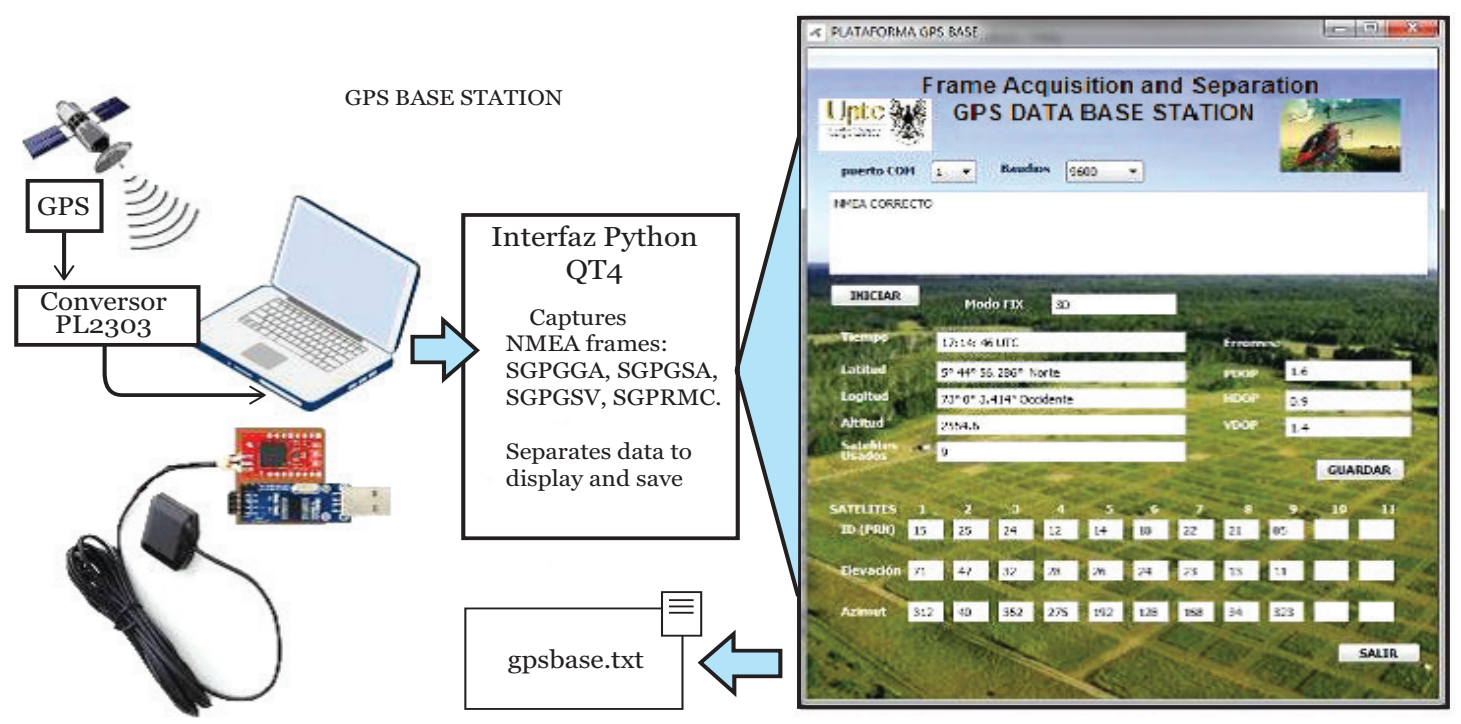

Fig. 3. DGPS Differential correction platform. Source: Authors

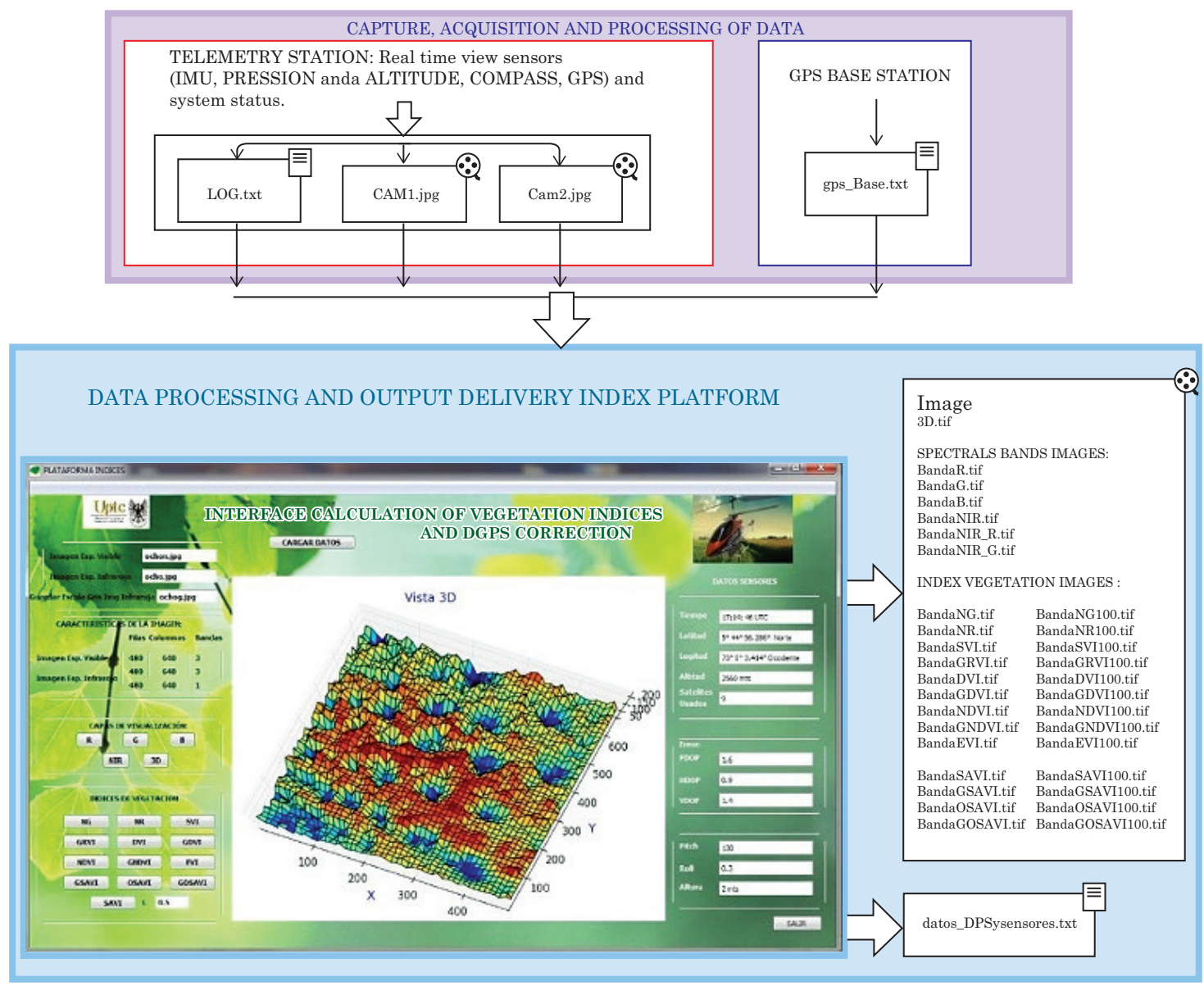

Fig. 4. Platform for calculating vegetation indexes and 3D Map. 


\section{Indexes Platform}

Interface developed in Python code and QT4Designer. It performs data processing and delivers the results to diagnose the state of the crop. In this software the images captured by the visible and infrared spectrum camera are loaded together with the Log.txt file which is delivered by the Telemetry Station, and the history gpsbase.txt file. The interface performs three basic functions: processes images, makes DGPS differential correction, and displays data and final parameters (see Fig. 4). This software develops an image processing algorithm that allows the characterization and diagnosis of a productive agricultural unit.

The calculation of vegetation indexes: GNVI (green normalized vegetation index), RNVI (red normalized vegetation index), SVI (single vegetation index), GRVI (green red vegetation index), DVI (difference vegetative index), GDVI (green difference vegetation index), NDVI (Normalized Difference Vegetation Index), GNDVI (green normalized difference vegetation index), EVI (enhanced vegetation index,) SIAV (soil index adjusted vegetation), GSAVI (green soil adjusted vegetation index), OSAVI (optimized soil adjusted vegetation index), and GOSAVI (green optimized soil adjusted vegetation index) is performed by means of ratios and rectangularity among spectral bands with corrections based on land use. The constants used to determine each vegetation index were based on those used by satellite systems.
To establish crop diagnosis, image segmentation is performed according to vegetation indexes and the state of each crop or plant. As a result of the segmentation, vegetation and non-vegetation in the crop is determined by the intensity of the gray level image. The analysis to determine the general state of crop is carried out using the resulting segmentation images of each one of the vegetation indexes.

The visualization generated in the Index Platform indicates: attributes of used images; DGPS correction data of capture position; lift, twist and tilt of the UAV at the time of taking pictures; $3 \mathrm{D}$ figure of the studied terrain and, of course, each of the vegetation indexes showing raw data, with enhancement and segmentation.

\section{E. Analysis and Diagnosis}

The UAV system (see Fig. 5) was tested in a field of lettuce, because it allows better identification of the characteristics of the crop and soil, also it has a short harvest period. The terrain was delimited as for an experimental plot to conduct the study, presenting features that facilitate the analysis and diagnosis of the crop. Several photographs were taken to follow the phenological process where photograph 1 was taken starting on the fourth day after the planting, and then every picture was taken over a period of time (in days) of: 9, 15, 20, $25,30,35$ and 40 , having a total of 8 different time periods.

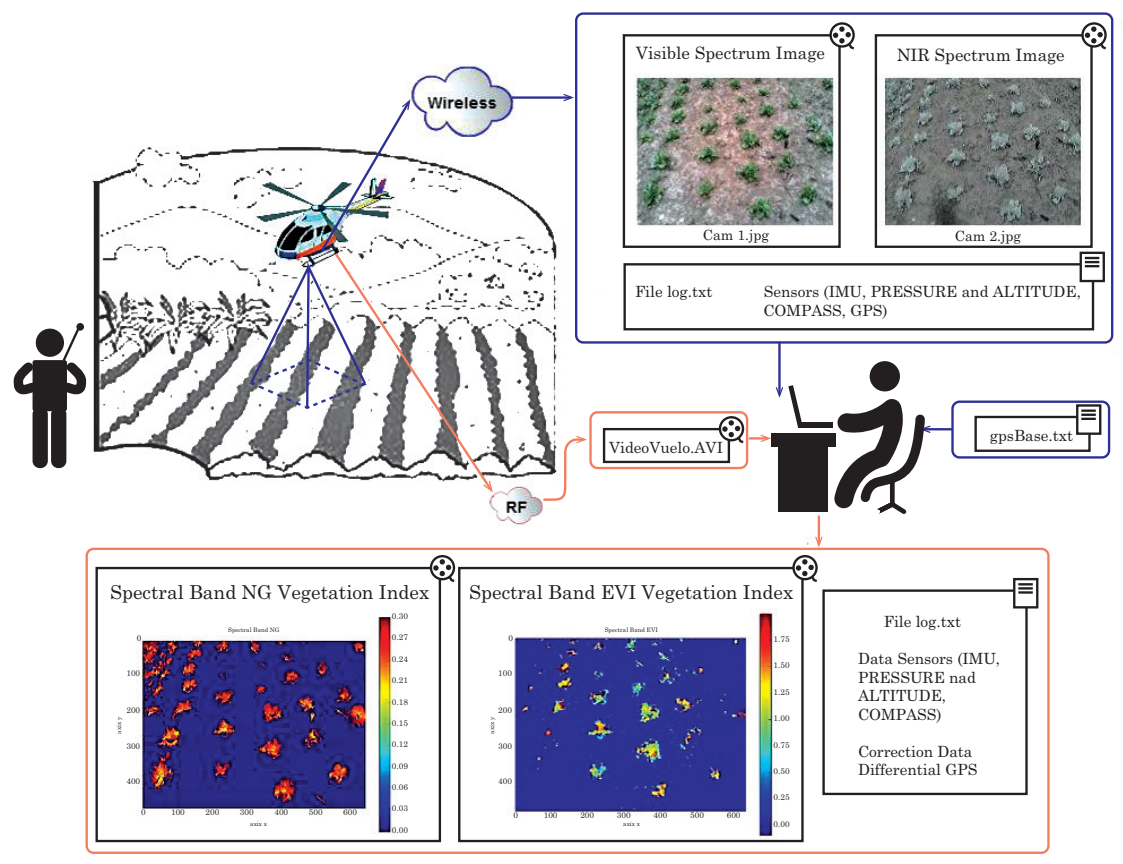

Fig. 5. General scheme of the system operation. Source: Authors 


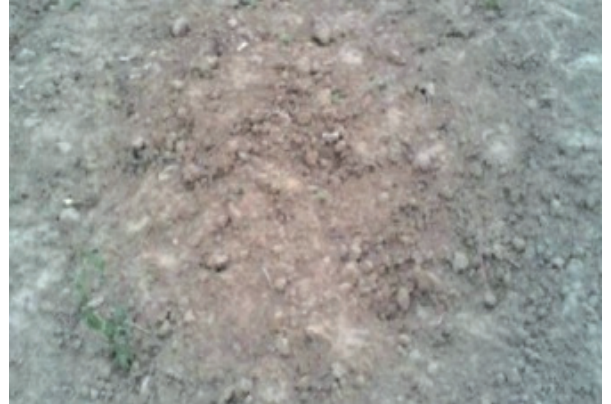

a)

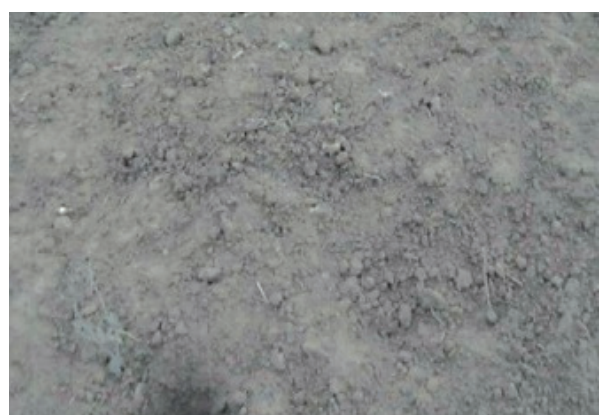

c)

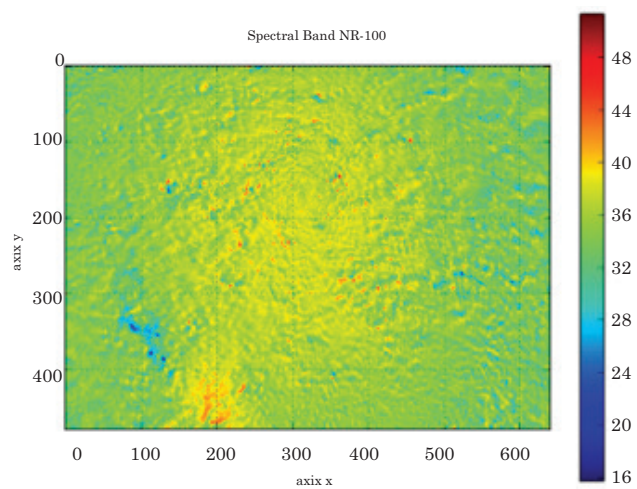

e)

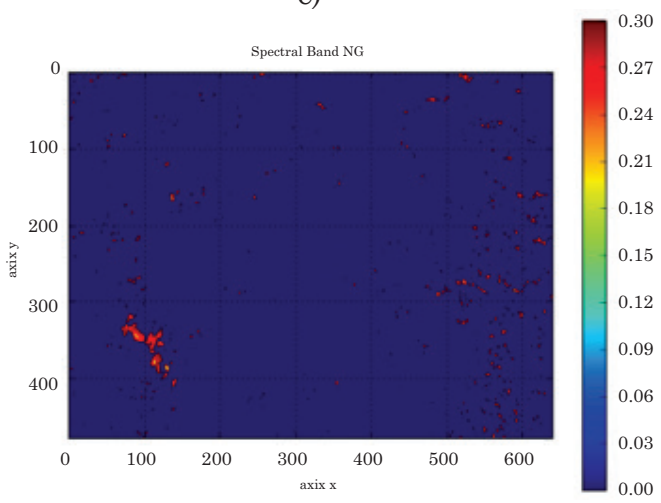

g)

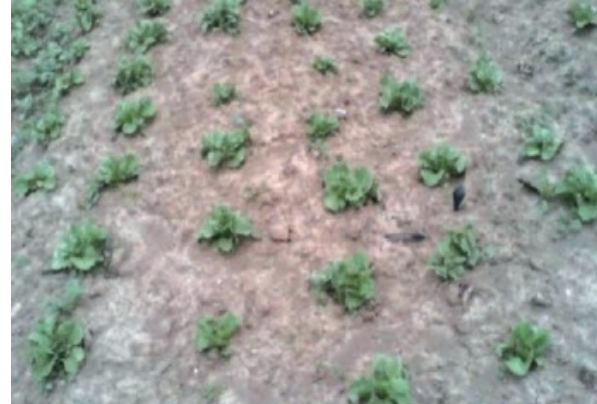

b)

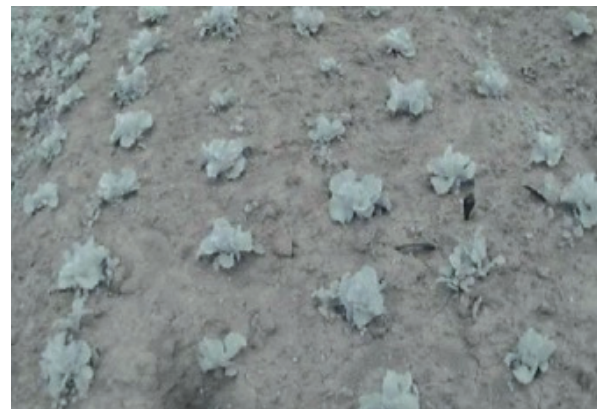

d)

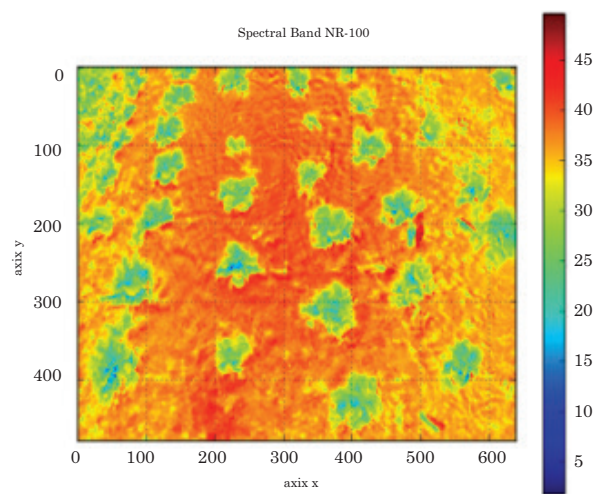

f)

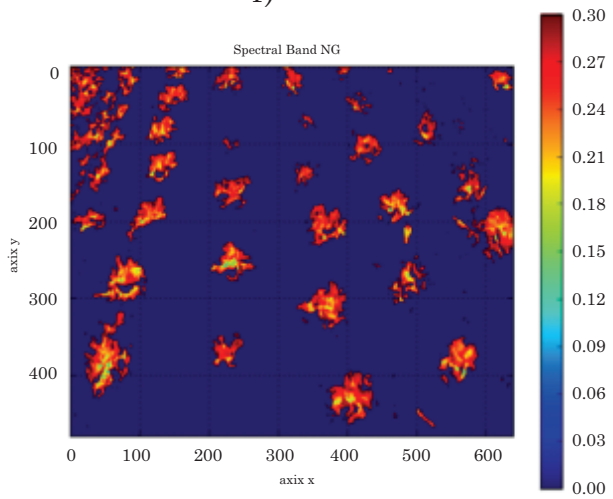

h)

Fig.6. Image spectrum: a) Image in the visible spectrum for bare soil, b) Image in the visible spectrum for soil with vegetation coverage, c) Image in the NIR spectrum for bare soil, d) Image in the NIR spectrum for soil with vegetation coverage, e) and f) RN Vegetation Index, ,g) and h) Vegetation Index image with image segmentation. Source: Authors 
For crop analysis and diagnosis, the used images are the ones corresponding to the time of planting and six weeks later. Thus, the changes occurring in the crop during its most important phenological phases are determined. Figure 6 shows the images captured by the system and processed using the algorithm in Python, both for the bare soil and the growing crop. One of the calculated vegetation indexes is shown as well as the vegetation segmentation procedure according to the nominal scales of the indexes that are used to discriminate between vegetation and non-vegetation coverage. The scale values for coverage of these two types highlight the changes in the index scale values according to crop growth.

The Red Normalized Vegetation Index RNVI (see Fig. $6 \mathrm{~g}$ and $6 \mathrm{~h}$ ) was the best one that provided feasible analysis features. Structural changes in the vines are observed, allowing identification of a homogeneous growth in this section of the crop. Each plant represents a physiognomy with a high content of biomass and good concentration of chlorophyll in the leaves as well as an adequate level of humidity; Generally speaking, it can be inferred that the leaf area is distributed properly, favoring the growth and development of each plant.

\section{CONCLUSIONS}

For the development of this project, five programming languages were integrated (HTML, JavaScript, Node.Js, C ++ and Python) which together complement each software tool (Station Telemetry, GPS Base Station, Indexes Platform), making it possible to generate a base from which different applications for civilian use can be developed, especially the monitoring of crops, damage assessment, search and rescue, location of natural resources, infrastructure inspection, forestry studies, security applications and everything related to precision agriculture, since all these applications must adapt an implementation of similar algorithms for handling of this type of images.

Some vegetation indexes show better characteristics and results than others, but all of them allow for the quantification of plant information. This project should continue with the adjustment and correction of the obtained values for cases of diseases, pests, irrigation, nutrition and application of inputs in specific crops.

\section{ACKNOWLEDGEMENTS}

The authors are grateful to the research groups DSP-UPTC and Macrypt of UNILLANOS for the support in the development of this project.

\section{REFERENCES}

[1] R. Sugiura, T. Fukagawa, N. Noguchi, K. Ishii, Y. Shibata, and K. Toriyama, "Field information system using an agricultural helicopter towards precision farming," in IEEE/ASME International Conference on Advanced Intelligent Mechatronics, 2003, vol. 2, pp. $1073-1078$. DOI:10.1109/aim.2003.1225491

[2] R. Sugiura, N. Noguchi, and K. Ishii, "Remote-sensing Technology for Vegetation Monitoring using an Unmanned Helicopter," Biosyst. Eng., vol. 90, no. 4, pp. 369379, 2005. DOI:10.1016/j.biosystemseng.2004.12.011

[3] M. Bragachini, A. Méndez, F. Proietti, and F. Scaramuzza, "Proyecto Agricultura de Precisión," INTA Manfredi, 2006. [En línea]. Disponible en: http://cosechaypostcosecha.org/data/folletos/FolletoAgriculturadePrecision.pdf.

[4] C. González, J. Sepúlveda, R. Barroso, F. Fernández, F. Pérez, and J. Lorenzo, "Sistema para la generación automática de mapas de rendimiento. Aplicación en la agricultura de precisión," Idesia, vol. 29, no. 1, pp. 59-69, 2011. DOI:10.4067/S0718-34292011000100009

[5] J. Peñafiel and J. Zagas, Fundamentos del sistema GPS y aplicaciones en la topografía. Madrid, 2001, pp. 1-135. F. Medeiros, A. Santos, M. Gonzatti, V. Oliviera, and M. Landerhal, "Utilização de umveículo aéreo nãotripulado ematividades de imageamento georeferenciado," Ciência Rural, vol. 38, no. 8, pp. 2378-2378, 2008. DOI:10.1590/S0103-84782008000800046

[7] X. Burgos, A. Ribeiro, A. Tellaeche, G. Pajares, and C. Fernández, "Analysis of natural images processing for the extraction of agricultural elements," Image Vis. Comput., vol. 28, no. 1, pp. 138-149, 2010. DOI:10.1016/j. imavis.2009.05.009

[8] D. J. Mulla, "Twenty five years of remote sensing in precision agriculture: Key advances and remaining knowledge gaps," Biosyst. Eng., vol. 114, no. 4, pp. 358371, 2013. DOI:10.1016/j.biosystemseng.2012.08.009

[9] J. Torres-Sánchez, F. López-Granados, A. I. De Castro, and J. M. Peña-Barragán, "Configuration and Specifications of an Unmanned Aerial Vehicle (UAV) for Early Site Specific Weed Management," PLoS One, vol. 8, no. 3, pp. 1-15, 2013. DOI:10.1371/journal.pone.0058210

[10] A. Castro, J. Peña, L. Garcia, and F. López, "Discriminación de malas hierbas crucíferas en cultivos de invierno para su aplicación en agricultura de precisión," in XIII Congreso de la Asociación Española de TeledetecciónCalatayud, 2009, pp. 61-64.

[11] Q. Du, B. Luo, and J. Chanussot, "Using High-Resolution Airborne and Satellite Imagery to Assess Crop Growth and Yield Variability for Precision Agriculture," Proc. IEEE, vol. 101, no. 3, pp. 582 - 592, 2012. DOI:10.1109/JPROC.2012.2196249 